\title{
Decision Making by Austin, Texas, Residents in Hypothetical Tornado Scenarios*
}

\author{
David M. Schultz, ${ }^{+, \# ~ E v e ~ C . ~ G r u n t F e s t, ~}{ }^{\circledR}$ MARy H. HAyden, \& Charles C. Benight,** \\ SHELDON DROBOT, \& AND LINDSEY R. BARNES ${ }^{++}$ \\ ${ }^{+}$Division of Atmospheric Sciences, Department of Physics, University of Helsinki, and Finnish Meteorological Institute, \\ Helsinki, Finland, and Centre for Atmospheric Science, School of Earth, Atmospheric and Environmental Sciences, \\ University of Manchester, Manchester, United Kingdom \\ @ Social Science Woven into Meteorology, University of Oklahoma, Norman, Oklahoma \\ ${ }^{\&}$ Research Applications Laboratory, National Center for Atmospheric Research, Boulder, Colorado \\ ** Department of Psychology, University of Colorado at Colorado Springs, Colorado Springs, Colorado \\ ${ }^{++}$enXco, Denver, Colorado
}

(Manuscript received 12 February 2010, in final form 12 April 2010)

\begin{abstract}
One of the goals of the Warning Project is to understand how people receive warnings of hazardous weather and subsequently use this information to make decisions. As part of the project, 519 surveys from Austin, Texas, floodplain residents were collected and analyzed. About $90 \%$ of respondents understood that a tornado warning represented a more serious and more likely threat than a tornado watch. Most respondents $(86 \%)$ were not concerned about a limited number of false alarms or close calls reducing their confidence in future warnings, suggesting no cry-wolf effect. Most respondents reported safe decisions in two hypothetical scenarios: a tornado warning issued while the respondent was home and a tornado visible by the respondent while driving. However, nearly half the respondents indicated that they would seek shelter from a tornado under a highway overpass if they were driving. Despite the limitations of this study, these results suggest that more education is needed on the dangers of highway overpasses as shelter from severe weather.
\end{abstract}

\section{Introduction}

Weather forecasters and emergency managers aim to provide accurate and timely warnings for hazardous weather so that people take the appropriate actions to protect life and property. Common assumptions are that people receive this information, understand it, know what to do, and, subsequently, make the best decisions (e.g., Doswell 2005; Parker et al. 2009).

The goal of the Warning Project (Benight et al. 2007; Drobot et al. 2007; Hayden et al. 2007) was to provide insight into the validity of these assumptions, with the aim

\footnotetext{
* Supplemental information related to this paper is available at the Journals Online Web site: http://dx.doi.org/10117/2010WCAS1067.s1.

\# Previous affiliation: Cooperative Institute for Mesoscale Meteorological Studies, University of Oklahoma, and NOAA/National Severe Storms Laboratory, Norman, Oklahoma.
}

Corresponding author address: Dr. David M. Schultz, Finnish Meteorological Institute, Erik Palménin Aukio 1, P.O. Box 503, FI-00101 Helsinki, Finland.

E-mail: david.schultz@fmi.fi of providing guidance for improving how future warnings are disseminated. The Warning Project was a National Science Foundation-funded research program (2003-08) that surveyed residents of Denver, Colorado, and Austin, Texas, about how they receive weather warnings for short-fuse weather events (e.g., tornadoes, flash floods), how they would prefer to receive warnings, and how they use this information to make decisions about their safety.

Drobot et al. (2007) examined the responses in the Warning Project surveys to determine the risk factors associated with people driving into flooded streets, finding that the following people were more likely to drive into flooded roads: those who did not take warnings seriously, those who were between the ages of 18 and 35, those who did not know that motor vehicles were involved in more than half of all flood fatalities, those who had not experienced a flood previously, and those who did not know they live in a flood-prone location. In this present article, we examine the decisions that people would make when facing hypothetical scenarios of a different short-fuse weather event: tornadoes. 
TABLE 1. Two hypothetical tornado scenarios: (a) Tornado at home, (b) tornado while driving.

(a) I am upstairs at home watching my favorite television show on a Saturday evening in October. The thunder and rain in the background is getting louder and louder. Hail is now crashing against my windows. Suddenly, I see a tornado warning at the bottom of the television screen stating that a tornado has been sighted in the Austin area and is moving in the direction of my home. The warning states "The safest place to be during a tornado is in a basement. Get under a workbench or other piece of sturdy furniture. If no basement is available, seek shelter on the lowest floor of the building in an interior hallway or room such as a closet. Use blankets or pillows to cover your body and always stay away from windows."

(b) I am driving east on Martin Luther King Blvd. near Airport Blvd. at 3 P.M. on an August afternoon to meet some friends. It's been pouring for the last $20 \mathrm{~min}$, and I see lightning everywhere. I look to my right and see what looks like a funnel cloud begin to drop from the sky not too far to the south. Traffic begins to slow down as the hail becomes more intense. I hear over the radio that a tornado warning has been issued for central Travis County: "The safest place to be during a tornado is in a basement. Get under a workbench or other piece of sturdy furniture. If no basement is available, seek shelter on the lowest floor of the building in an interior hallway or room such as a closet. If in mobile homes or vehicles, evacuate them and get inside a substantial shelter."

\section{Methods}

Two survey instruments were developed to assess perceptions of short-fuse weather hazards in Denver and Austin, and both are available as electronic supplements to this article (online at http://dx.doi.org/10117/ 2010WCAS1067.s1). Each survey was tailored for the risks, local hazards, and geography of each city. The survey procedure was conducted based on Dillman (2000) for mail and Internet questionnaires. The construction and implementation of the survey are described in Benight et al. (2007) and Hayden et al. (2007). Although the Austin survey asked questions about both flash floods and tornadoes, the Denver survey did not ask any tornado-specific questions. In this article, we focus on the tornado-specific questions from Austin. Data analysis was conducted using the SPSS (originally, Statistical Package for the Social Sciences) software package. All tests of statistical significance were conducted using the chi-square $\chi^{2}$ test (e.g., Wilks 1995, 133-134) with one degree of freedom, except for tests on the data in Fig. 2 that used nine degrees of freedom.

\section{Respondents' perceptions on tornadoes}

Most respondents correctly knew that a tornado warning indicates a more serious threat $(89 \%)$ or more likely threat $(90 \%)$ than a tornado watch, which is comparable to the results of other similar surveys (e.g., Pifer and Mogil 1978; Legates and Biddle 1999; Balluz et al. 2000; Gruntfest et al. 2002, p. 41). However, when respondents in other studies are asked to define these terms in open-ended questions, they tend to do more poorly (e.g., Sherman-Morris 2010), suggesting a need to better understand these discrepancies if the National Weather Service is to communicate using these terms effectively.

Only $10 \%$ of respondents believed that officials were too sensitive to the possibility of tornadoes; $11 \%$ preferred fewer warnings, even if it meant more false alarms or close calls; and $14 \%$ said that one or two tornado false alarms or close calls would reduce their confidence in future warnings. These data indicate that most respondents were not overly concerned about the cry-wolf effect (e.g., Dow and Cutter 1998; Drabek 2001) for tornadoes, consistent with Barnes et al. $(2007,2009)$.

Most respondents $(76 \%)$ would not consider a tornado in Austin a life-threatening risk to them. [An average of 7 days decade ${ }^{-1}$ have one or more tornadoes within 25 miles of Austin (Fig. 1 in Doswell 2003).] Of all respondents, $40 \%$ said their home had a basement, tornado shelter, or an interior room where they could seek shelter, and $63 \%$ of all respondents said that they had a plan to keep themselves and their family safe in a tornado. Respondents whose homes did not have a basement, tornado shelter, or interior room were equally as likely to have a family safety plan as not. In contrast, respondents whose homes had a shelter were nearly 5 times more likely to have a plan for keeping their family safe than those without such protection $(83 \%$ versus $17 \%$ of all respondents).

Compared with those who had no safety plan, respondents who had plans were more likely to believe they would experience a tornado in their lifetime (79\% versus $\left.60 \%, \chi^{2}=20, p<0.001\right)$, less likely to believe that one or two tornado false alarms or close calls would reduce their confidence in future warnings ( $83 \%$ versus $89 \%, \chi^{2}=3.1$, $p=0.08$ ), and less likely to believe that officials were too sensitive to the possibility of tornadoes ( $87 \%$ versus $92 \%$, $\left.\chi^{2}=3.0, p=0.09\right)$

\section{Tornado scenarios}

To understand how the respondents pictured their actions during a tornado warning, the respondents were asked to put themselves into two hypothetical situations. These situations are referred to as the tornado-at-home and tornado-while-driving scenarios (Table 1).

\section{a. Tornado-at-home scenario}

The survey asked the respondents to imagine themselves in the scenario described in Table 1a. Although 
$82 \%$ of people said they were knowledgeable enough to know what to do to keep their family and themselves safe, only $62 \%$ felt completely capable of keeping themselves and their family safe in this scenario. Generally, respondents would be moved to action, with only $3 \%$ not taking any action. Almost $18 \%$ would leave their house to get out of the path of the tornado. Respondents whose homes had basements, storm shelters, or interior rooms were more likely to indicate that they would stay at home during tornadoes than those without such protection ( $88 \%$ versus $\left.79 \%, \chi^{2}=7.4, p=0.006\right)$, results consistent with Balluz et al. (2000).

\section{b. Tornado-while-driving scenario}

The survey asked the respondents to imagine facing the scenario in Table 1b. If the respondents did not drive, they were asked to skip questions related to this scenario. In contrast to the tornado-at-home scenario, only $47 \%$ of respondents felt confident that they were capable of keeping themselves and their family safe, indicating that the tornado-while-driving scenario was perceived as more threatening to respondents.

If caught in this situation, $72 \%$ of the respondents said that they would leave their car and seek shelter, 39\% said that they would stay in their car and drive away from the tornado, and $19 \%$ said that they would stop their car and remain in it. (Because these questions were asked independently, responses could exceed $100 \%$.) Some respondents $(16 \%)$ would attempt to drive through the storm to get home to loved ones and/or pets. There were no statistically significant differences for gender for these action decisions.

A disturbing result from this scenario was that almost half of respondents ( $45 \%$ ) said that they would stop their car under a highway overpass and climb up in the rafters of the overpass for safety (Fig. 1), although some respondents said that there was no overpass near the site of the hypothetical tornado in the question. This possible action was placed in the survey because of our perception that people were emulating either a well-publicized and award-winning video from April 1991 showing a group of people cowering under an overpass on the Kansas Turnpike while a tornado passes nearby or a similar scene in the movie Twister, both suggesting that overpasses are a safe place to shelter from a tornado. Indeed, Bartlett (2005) showed that the percentage of people surveyed who would shelter under an overpass rose from $48 \%$ to $83 \%$ after a single viewing of the Kansas Turnpike video, despite $88 \%$ of respondents claiming to know about severe weather preparedness. Unfortunately, people following such behavior have died or been severely injured because the accelerating wind through these small areas batters the area with debris and blows people out from

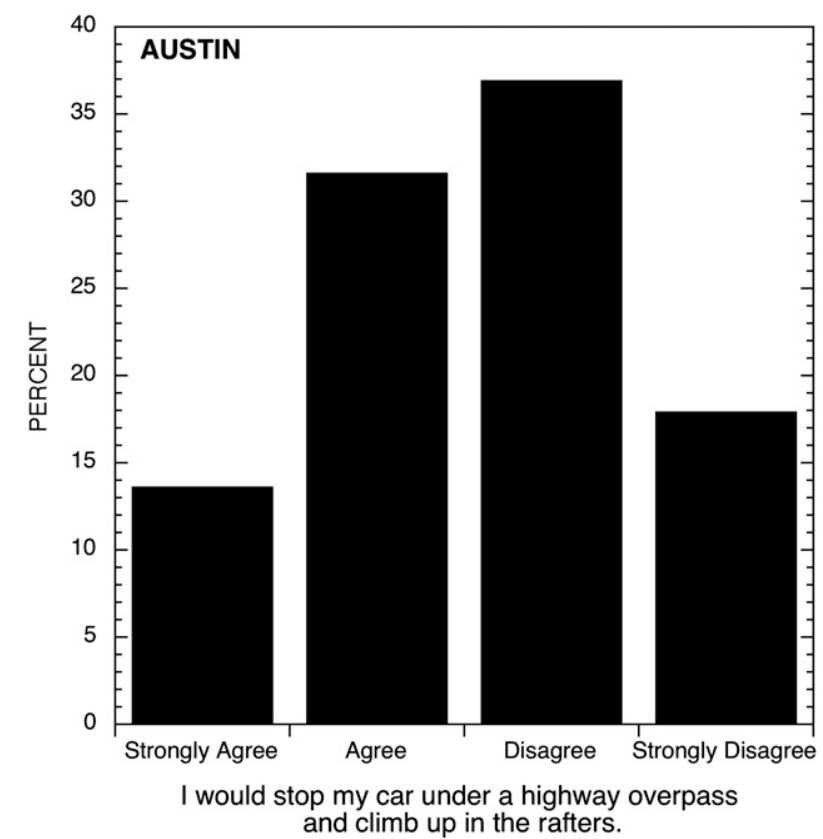

FIG. 1. In the tornado-while-driving scenario, respondents were asked their opinion about the statement "I would stop my car under a highway overpass and climb up in the rafters." The vertical axis is the percentage (\%) of all 491 respondents to this question in each category.

under the overpass (e.g., Brown et al. 2002; Daley et al. 2005). Furthermore, stopped traffic congests the highway, preventing the flow of traffic away from an approaching tornado [one way to flee a tornado recommended by Hammer and Schmidlin (2002)] and reducing access for emergency vehicles. Thus, the message from the National Weather Service that highway overpasses are dangerous places during tornadoes (Miller et al. 1999) needs to be more strongly conveyed to the public (e.g., American Meteorological Society 2000; Bartlett 2005).

The majority of respondents who strongly agreed that they would climb into the rafters also strongly agreed that they were confident in their ability to keep themselves and their family safe (Fig. 2). In contrast, of people who strongly disagreed that they would climb into the rafters, the two largest groups were those who strongly agreed and those who strongly disagreed that they were capable of keeping themselves and their family safe (Fig. 2). Finally, respondents who did not have strong feelings about climbing into the rafters also did not feel strongly either way about their ability to keep themselves and their family safe (Fig. 2). These four distributions were statistically distinct $\left(\chi^{2}=45, p<0.001\right)$. Thus, people who were confident in their safety abilities were more likely to report that they would make the wrong decision, whereas people who were not confident in their safety abilities were more likely to report they would make the 


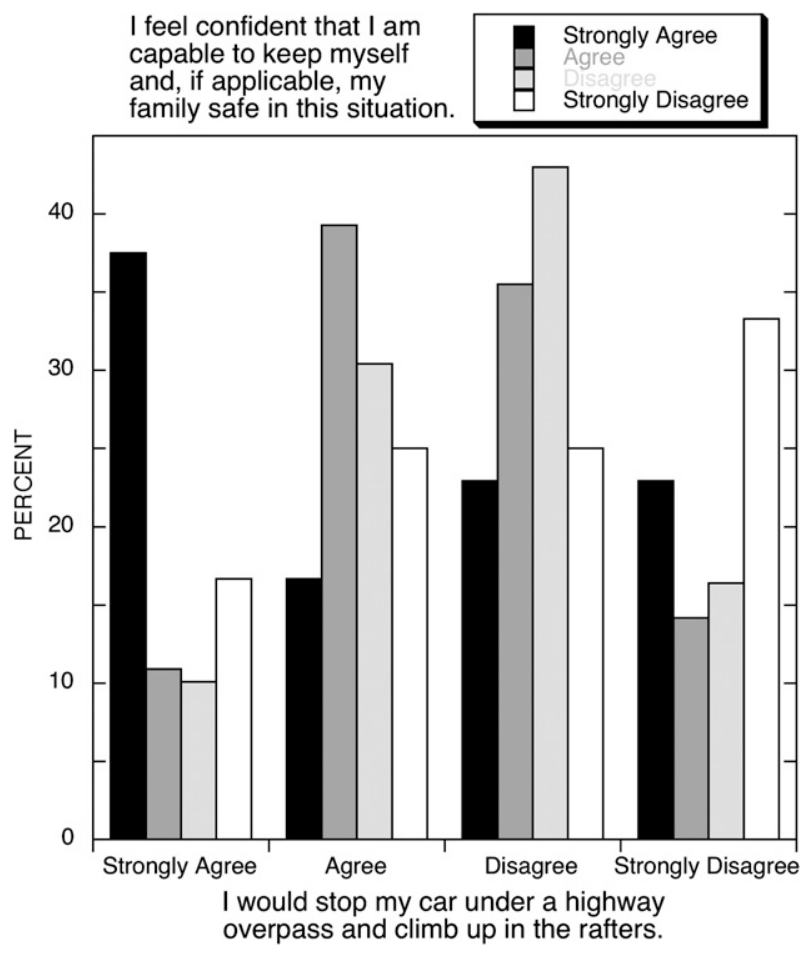

FIG. 2. In the tornado-while-driving scenario, respondents were asked their opinion about the statement "I would stop my car under a highway overpass and climb up in the rafters," displayed as a function of the percentage (\%) responding in each category to this statement: "I feel confident that I am capable to keep myself and, if applicable, my family safe in this situation." There were 486 respondents who supplied valid responses to both questions.

right decision. Consequently, both groups of people require education about how to think about safety during a tornado warning.

\section{Discussion}

Some caution is warranted before generalizing the results of this study. First, this survey was only given to Austin floodplain residents; residents of other locations might respond differently. For example, using the Warning Project survey results, Drobot et al. (2007) and Hayden et al. (2007) found differences in responses to flash flooding between Austin and Denver residents, perhaps because of different emphases on public awareness campaigns, frequencies of floods, or geographical hazard cues. Thus, future warning research that attempts to replicate these findings should use more representative sampling.

Second, some inconsistency exists between our results and other published studies that used different methods. Specifically, we found that false alarms do not reduce confidence in future warnings, yet Simmons and Sutter
(2009), using a National Weather Service dataset of tornado warnings and casualties, found that tornadoes occurring in areas with a higher false-alarm ratio kill and injure more people than tornadoes occurring in areas with a lower false-alarm ratio. However, further study addressing the relationship between the number of false alarms and confidence in future warnings is beyond the scope of this study.

Third, the survey could have been improved by asking about confirmation of the tornado threat as a possible action before any protective action. Such confirmation might include looking outside, calling a friend or relative for news, changing the television channel to one discussing the weather, or texting on a mobile phone for information.

Fourth, these results are likely specific to tornadoes, as well as possibly other short-fuse weather events such as flash floods and severe thunderstorms. Although some of the results from this paper can be compared to studies of hurricane preparedness and evacuations, the different time scales over which the warnings and threats apply raise questions about their generality to other warning situations.

Fifth, our results do not evaluate the different options available to the respondents nor do they question the information in the call-to-action statements issued by the National Weather Service (e.g., Farley 2007). For example, if the respondents chose not to shelter under an overpass, is the safer option lying in a ditch or driving away from the tornado? Similarly, we have little indication for why $18 \%$ of respondents would leave their house during a tornado warning. Do they live in an unsafe home, and would they feel safer driving away (e.g., Hammer and Schmidlin 2002; Farley 2007)?

Sixth, people's responses on a survey may differ from their behavior in real life (e.g., Dollard 1948/49). This result indicates that a more thorough investigation of risk requires behavioral studies, as well. For example, League (2009) examined videos people posted online (at YouTube.com) of themselves driving through flooded roads. Approximately half of the drivers intentionally drove across the flooded roads for fun or to film the results, whereas the other half acknowledged knowing there were warnings in effect and that driving across lowwater crossings could be deadly but said they "needed to go." This response was also noted by López-Marrero and Yarnal (2010) and is reminiscent of the $16 \%$ of respondents who would drive through the storm to reach loved ones or pets (section $4 \mathrm{~b}$ ). For many respondents in League's (2009) study, the perceived risk of losing a job was greater than the perceived risk of losing their life. Although Drabek (1999) focused on hurricane evacuations, he found that the emergent perception of risk and 
subsequent actions are dependent on multiple factors including, but not limited to, risk of loss of pay when leaving the worksite in response to a warning. Nonetheless, the majority of respondents in his study stated that decisions to take action in response to warnings were based on family and personal safety, not loss of pay. Consequently, the context in which people make decisions can be quite relevant to their ability to make safe decisions. The results of these and future behavioral studies should be examined to determine the importance of non-weather-related factors to decision making and to influence behavioral change when respondents are faced with imminent short-fuse weather hazards. These findings emphasize the need for the National Weather Service to recognize that it will take more than accurate, credible weather forecasts to change behavior of those at risk in hazardous situations.

\section{Summary}

Five hundred and nineteen surveys of floodplain residents in Austin, Texas, were collected and analyzed. The principal results are as follows:

- About $90 \%$ of respondents understood that tornado warnings are a greater threat than tornado watches.

- Sixty-three percent of respondents had a plan to keep their family safe from tornadoes at home, although only $41 \%$ had adequate in-home shelter.

- Most respondents ( $86 \%$ ) did not believe that a limited number of false alarms or close calls would reduce their confidence in future warnings.

- When faced with a tornado while at home, $82 \%$ of respondents would stay at home.

- When faced with a tornado while driving, $72 \%$ of respondents would seek shelter, $39 \%$ would drive away from the tornado, and 19\% would shelter in their car.

- About half (45\%) of respondents would stop their car under an overpass and climb into the rafters during a tornado.

These results indicate the perceptions that Austin floodplain residents have of tornadoes and tornado warnings and the potential actions that they would take when faced with two different tornado scenarios. In particular, many felt strongly that seeking shelter under a highway overpass was a safe action, pointing to the need for better education about the safety of seeking shelter under highway overpasses during severe weather.

Acknowledgments. The Warning Project was funded by National Science Foundation Grant CMS-0301392 to Gruntfest and Benight. Schultz was partially funded by the NOAA/Office of Oceanic and Atmospheric Research under NOAA-University of Oklahoma Cooperative Agreement NA17RJ1227, U.S. Department of Commerce, and by Vaisala Oyj. The National Center for Atmospheric Research is funded by the National Science Foundation. We thank three anonymous reviewers for their comments, which improved this manuscript.

\section{REFERENCES}

American Meteorological Society, 2000: Tornado preparedness and safety. Bull. Amer. Meteor. Soc., 81, 1061-1065.

Balluz, L., L. Schieve, T. Holmes, S. Kiezak, and J. Malilay, 2000: Predictors for people's response to a tornado warning: Arkansas, 1 March 1997. Disasters, 24, 71-77.

Barnes, L. R., E. C. Gruntfest, M. H. Hayden, D. M. Schultz, and C. Benight, 2007: False alarms and close calls: A conceptual model of warning accuracy. Wea. Forecasting, 22, 1140-1147; Corrigendum: False alarm rate or false alarm ratio? 24, 1452-1454.

Bartlett, J., 2005: The impact of the media on false public perception of tornado safety precautions. M.S. thesis, Dept. of Sociology, Oklahoma State University, $81 \mathrm{pp}$.

Benight, C. C., E. C. Gruntfest, M. Hayden, and L. Barnes, 2007: Trauma and short-fuse weather warning perceptions. Environ. Hazards, 7, 220-226.

Brown, S., P. Archer, E. Kruger, and S. Mallonee, 2002: Tornadorelated deaths and injuries in Oklahoma due to the 3 May 1999 tornadoes. Wea. Forecasting, 17, 343-353.

Daley, W. R., S. Brown, P. Archer, E. Kruger, F. Jordan, D. Batts, and S. Mallonee, 2005: Risk of tornado-related death and injury in Oklahoma, May 3, 1999. Amer. J. Epidemiol., 161, 1144-1150.

Dillman, D. A., 2000: Mail and Internet Surveys: The Tailored Method. Wiley, 464 pp.

Dollard, J., 1948/49: Under what conditions do opinions predict behavior? Public Opin. Quart., 12, 623-632.

Doswell, C. A., III, 2003: Societal impacts of severe thunderstorms and tornadoes: Lessons learned and implications for Europe. Atmos. Res., 67-68, 135-152.

- 2005: Progress toward developing a practical societal response to severe convection (2005 EGU Sergei Soloviev Medal Lecture). Nat. Hazards Earth Syst. Sci., 5, 1-12.

Dow, K., and S. L. Cutter, 1998: Crying wolf: Repeat responses to hurricane evacuation orders. Coastal Manage., 26, 237-252.

Drabek, T. E., 1999: Disaster-induced employee evacuation. Institute of Behavioral Science, Program on Environment and Behavior Monogr., No. 60, University of Colorado, 55-81.

_ 2001: Disaster warning and evacuation responses by private business employees. Disasters, 25, 76-94.

Drobot, S. D., C. Benight, and E. C. Gruntfest, 2007: Risk factors for driving into flooded roads. Environ. Hazards, 7, 227-234.

Farley, J. E., 2007: Call-to-action statements in tornado warnings: Do they reflect recent developments in tornado-safety research? Int. J. Mass Emerg. Disasters, 25, 1-36.

Gruntfest, E., K. Carsell, and T. Plush, 2002: An evaluation of the Boulder Creek local flood warning system. Rep. for the Urban Drainage and Flood Control District, Boulder City/County Office of Emergency Management, $110 \mathrm{pp}$.

Hammer, B., and T. W. Schmidlin, 2002: Response to warnings during the 3 May 1999 Oklahoma City tornado: Reasons and relative injury rates. Wea. Forecasting, 17, 577-581. 
Hayden, M. H., S. Drobot, S. Radil, C. Benight, E. C. Gruntfest, and L. R. Barnes, 2007: Information sources for flash flood warnings in Denver, CO, and Austin, TX. Environ. Hazards, 7, 211-219.

League, C. E., 2009: What were they thinking: Using YouTube to observe driver behavior while crossing flooded roads. M.A. thesis, Dept. of Geography and Environmental Studies, University of Colorado at Colorado Springs, $76 \mathrm{pp}$.

Legates, D. R., and M. D. Biddle, cited 1999: Warning response and risk behavior in the Oak Grove-Birmingham, Alabama, tornado of 08 April 1998. Quick Response Rep. 116, Natural Hazards Center, University of Colorado at Boulder. [Available online at www.colorado.edu/hazards/research/qr/qr116/qr116.html.]

López-Marrero, T., and B. Yarnal, 2010: Putting adaptive capacity into the context of people's lives: A case study of two flood-prone communities in Puerto Rico. Nat. Hazards, 52, 277-297.
Miller, D. J., C. A. Doswell III, H. E. Brooks, G. J. Stumpf, and E. Rasmussen, cited 1999: Highway overpasses as tornado shelters: Fallout from the 3 May 1999 Oklahoma/Kansas violent tornado outbreak. Slide presentation, 24th Annual Meeting of the National Weather Association, Biloxi, MS, NWA. [Available online at http://www.srh.noaa.gov/oun/?n=safety-overpass.]

Parker, D. J., S. J. Priest, and S. M. Tapsell, 2009: Understanding and enhancing the public's behavioural response to flood warning information. Meteor. Appl., 16, 103-114.

Pifer, B., and H. M. Mogil, 1978: NWS hazardous weather terminology. Bull. Amer. Meteor. Soc., 59, 1583-1588.

Sherman-Morris, K., 2010: Tornado warning dissemination and response at a university campus. Nat. Hazards, 52, 623-638.

Simmons, K. M., and D. Sutter, 2009: False alarms, tornado warnings, and tornado casualties. Wea. Climate Soc., 1, 38-53.

Wilks, D. S., 1995: Statistical Methods in the Atmospheric Sciences. Academic Press, 467 pp. 